\title{
Games and Network Structures on Corruption, Income Inequality, and Tax Control
}

\author{
Elena Gubar ${ }^{1}$, Edgar J. Sánchez Carrera $^{2}$, Suriya Kumacheva ${ }^{1}$, \\ Ekaterina Zhitkova ${ }^{1}$, Galina Tomilina ${ }^{3}$ \\ 1 Faculty of Applied Mathematics and Control Processes, St. Petersburg State \\ University, 7/9 Universitetskaya nab., St. Petersburg, 199034 Russia. \\ 2 Department of Economics, Society and Politics. University of Urbino Carlo Bo, Italy. \\ Reseach Member at CIMA from Autonomous University of Coahuila, Mexico. \\ 3 EPAM Systems, Inc. \\ E-mail: e.gubar@spbu.ru \\ s. kumacheva@spbu.ru \\ e.zhitkova@spbu.ru \\ edgar.sanchezcarrera@uniurb.it \\ g.tomilina@yandex.ru
}

\begin{abstract}
The income tax system is the main instrument of fiscal policy that aims to improve income distribution and economic growth, but the problem arises when there is corrupt behavior in that system. While the tax audit is a tax control tool that is costly, the tax system should guarantee, however, the instruments for tax collection. In this research work, we formulate a model in which all taxpayers decide to pay taxes or not according to their personal income, individual preferences with respect to the audit and tax control information perceived in their social environment. We develop a theoretical model to study the structure of citizen networks that must pay taxes. First, we assume that citizens are classified by two social groups, the rich and the poor. When all citizens are taxpayers, but public authorities are corrupt, we show that the poor group is the most affected by corruption. However, when taxpayers are corrupt or tax evaders, we implement mechanisms to audit and control this corrupt behavior. Hence, we show that this situation of corruption and control of tax payments can be represented by several well-known theoretical games. Then, we apply the evolutionary theory of the game in the network considering that each taxpayer receives information from his $\backslash$ her neighbors about the probability of audit and that he $\backslash$ she could react according to his $\backslash$ her risk status and real income. Such behavior forms a group of informed agents that propagate the information beyond the proportions of the informed and uninformed contributors that are modified. Our evolutionary model in the structure of the network describes the changes in the population of taxpayers driven by the impact of information on the future fiscal audit. Our simulation analysis shows that the initial and final preferences of taxpayers depend on important parameters, that is, taxes and fines, audit information and costs.
\end{abstract}

Keywords: behavioral economics; corrupt behavior; income distribution; income taxation system; network Games; population games. 


\section{Introduction}

The misuse of public office for private gain in a manner that contravenes the rules of the game (so it is defined corruption) has been found responsible for losses in GDP growth (Abed and Davoodi, 2000; Leite and Weideman, 1999; Mauro,1996; Tanzi and Davoodi, 2000), in the ratio of investments to GDP (Ades and Di Tella, 1997; Mauro,1996; Tanzi and Davoodi,1998), in the ratio of public education and public health spending to GDP (Mauro, 1998), in the ratio of tax revenues to GDP (Ghura, 1998), in some measures of government revenues to GDP ratio (Tanzi and Davoodi, 2000), and finally in the amount of foreign direct investment (Habib and Zurawicki, 2001).

Corruption may also affect income inequality by means of other variables like quality and quantity of public services (especially in the education and health sectors), by reducing the effectiveness of public spending. Inequality of opportunities like having a healthy body and equal access to a decent education may have reflections on future income perspectives, and therefore on income inequality. Hence, corruption is likely to affect the investment in and formation of human capital through its impact on the effectiveness, outcomes, and composition of public spending, which in turn may undermine long term sustainable development, economic growth and equality.

Both theoretically and empirically, it has been shown how corrupt practices on the part of public officials can compromise growth and exacerbate inequalities by distorting incentives, destroying opportunities, squandering resources, and perverting public policy. For example, some research papers studying the relationship between corruption and income inequality are, among others, the following:

1. (Andres and Ramlogan-Dobson, 2011) shows that lower corruption is associated with higher inequality in Latin American countries. This result is in contrast with previous studies but the panel of LA countries makes such results robust for several reasons, institutional and cultural aspects.

2. (Apergis at al., 2010) investigate the causality between corruption and income inequality within a multivariate framework for the U.S. over the period 1980 to 2004. Using cointegration techniques, they detect a long-run relationship between corruption and income inequality and a bidirectional Granger-causality between these two variables.

3. (Chong and Gradstein, 2007) investigates theoretically and empirically the relationship between inequality and institutional quality, placing its findings (of a double causality between these two variables) in the context of the conflicting evidence as to how corruption affects inequality.

4. (Dincer and Gunalp, 2005) use a panel dataset for the US states and find robust evidence that an increase in corruption (measured by the number of convictions for crimes related to corruption) increases the Gini coefficient of income inequality and decreases income growth. They justify this fact by saying that the benefits of corruption are likely to flow to better-connected individuals and groups who typically belong to higher income groups. Better connected individuals are more likely to get the most profitable government projects, undermining the government's ability to ensure equitable distribution of resources.

5. In Indonesia, (Olken, 2005) studies the extent of corruption in a large transfer program distributing subsidized rice to poor households. Using survey data, he finds that losses due to corruption may be large enough to outweigh the redis- 
tributive potential of this social welfare program because about $18 \%$ of the rice disappeared between the time it left government warehouses and the time it reached poor households, and comparing the costs of this corruption with the potential redistributive benefits from the program, corruption was sufficiently large to outweigh the intended benefits of the program. This suggests that corruption can seriously hamper the redistributive efforts of social programs, so income inequality.

6. (De Gregorio and Lee, 2002) and (Li et al., 1998) find that average years of schooling, and other educational factors, contribute positively to a more equal distribution of income. (Li et al., 1998) and (Barro, 2000) are examples of others who also find that more schooling appears to have an income equalizing effect.

7. (Gupta et al., 2002) shows that high and rising corruption increases income inequality and poverty. They conclude that policies that reduce corruption will most likely reduce income inequality and poverty as well.

8. (Gupta et al., 2000), based on a cross-country analysis, find that corruption increases income inequality through lower economic growth, biased tax systems favoring the wealthy and well connected, lower levels, and effectiveness of social spending, and unequal access to education and public services.

9. Using panel data from African countries, (Gymah-Brempong, 2001) claims that a one-point increase in the corruption index is associated with a seven-point increase in the Gini coefficient of income inequality. Despite the availability of a panel dataset, however, this author does not address the issue of causality.

This paper seeks to make a further contribution to the research analysis of corruption, income distribution, and tax control, by applying game theory, and network analysis as a powerful tool to study the behavioral dynamics of corruption in a tax system. The tax system is one of the most important mechanisms of state regulation. A significant part of this system is tax control, which provides receiving taxes and fees in the state budget. A wide class of models, such as (Chander and Wilde, 1998; Vasin and Morozov, 2005; and Boure and Kumacheva, 2010), have used a gametheoretical approach, where "the threshold rule" was formulated. This rule defines the value of auditing probability which is critical for the decision of taxpayers to evade taxation or not. However, in real life, it is difficult to implement tax inspections with the threshold probability because this process requires large investments from the tax authority, while it has a substantially limited budget. Hence, the tax authority needs to find a way to stimulate the population to pay taxes in accordance with their true level of income. Previous studies (see Nekovee et al., 2007, Tembine et al., 2010) have shown that information dissemination has a significant impact on the behavior of agents in various environments, such as the urban population, the social network, labor teams, etc.

Taking into account previous research (Accinelli and Sanchez Carrera, 2012; Antoci et al., 2014; Antunes et al., 2006; Apergis at al., 2010; Bardhan, 1997; Barro, 2000; Bloomquist, 2006; Kumacheva et al., 2018), this research paper studies the propagation of information about upcoming tax inspections as a tool to stimulate the population to pay taxes honestly. This approach allows the tax authority to optimize the collection of taxes within the strong limitation of the budget. In this research paper, we assume that the population of taxpayers is heterogeneous in its perception of such information. Additionally, to previous research (Gubar et al., 2015; 
Gubar et al., 2017a) susceptibility of each agent depends on its risk-status, due to his $\backslash$ her natural propensity to risk. As in previous studies we take into account three possible risk-statuses: risk-loving, risk-averse and risk-neutral. These three statuses define the behavior of taxpayers, according to their intentions to evade the tax payment. For example, risk-averse taxpayers prefer to avoid the punishment from the tax authority, therefore, they pay taxes. Risk-loving taxpayers choose risky behavior and try to evade the tax payment. Risk-neutral taxpayers follow to flexible and adaptive behavior, they can behave as a risk-loving or risk-averse taxpayers in different conditions. The economic environment of each individual also impacts the perceiving of incoming information. However, in this research study, we consider taxpayers that have risk-neutral status composing a population of taxpayers. The risk-neutral behavior model investigated in this paper is taken as the basis for studies of populations with different risk statuses (Gubar et al., 2019; Kumacheva et al., 2019). In contrast to many different works, where information transmits during random matches of agents, we consider only a structured population and hence information can be transferred only between connected agents.

Social connections of each taxpayer mathematically can be described by using network structures and their modifications. Here we assume that tax authority injects information about future audits to the population and thereby the initial share of Informed agents is formed. Informed agents can spread information over their contact network and thereby the ratio between informed and uninformed agents in a structured population is changed. Propagation of information also initiates the migration of economic agents between two subgroups: those who pay taxes honestly and those who evade payments. However in real-life situations, many agents communicate mostly with their family and friends, such sorts of interactions can be defined by the network of contacts (see Tembine et al., 2010; Gubar et al., 2015). According to all these reasons we formulate an evolutionary model on the network on the network which describes the variation of taxpayers' behavior. If a taxpayer switches on another status, then she transfers to the new subgroup, and thus the qualitative structure of the population is changed. This population process resembles an evolutionary game. Therefore, we can use the tools of evolutionary game theory, such as stochastic evolutionary dynamics, to describe the changes in the taxpayers' behavior. A taxpayer, who receives the opportunity to change her status following a revision protocol, chooses an opponent at random and switches from status $i$ to status $j$ according to the conditional rate (Sandholm, 2010; Gubar et al., 2017a; Sanchez Carrera et al., 2018). In other words, the taxpayer can compare his $\backslash$ her behavior with the behavior of the random agent. If the exampled strategy gives better payoff, then she changes her status (strategy). We estimate the initial and final distribution of taxpayers which prefer to evade taxation in a series of numerical simulations.

This paper is structured as follows. Section 2 develops a simple model showing that if all citizens are taxpayers according to income distribution, but there is corrupt behavior from public officials, then a group of poor citizens is the most affected. Section 3 considers that citizens can evade paying taxes, and so being corrupt citizens, then tax authority may consider an auditing mechanism or tax control which depends on both the tax rate and the penalty rate. Section 4 develops the network structure model for tax collection, while section 5 presents the numerical simulation on such networks structures and its modifications. Section 6 concludes the paper. 


\section{Corrupt Officials and Taxpayers}

There is a homogeneous population of $n$ taxpayers, each of them has an income $y_{i}, i=\overline{1, n}$. Without lost of generality, consider the two extreme income groups, i.e. the rich $R$ and the poor $P$. The public officials always perform acts of corruption on these two populations, as they want a bribe or part of the income of these citizens. Assume that public officials may overvaluate, $\bar{y}>y$ or undervaluate $\underline{y}<y$, the income of the citizens, where $y>0$ denotes the true valuation. However, this overvaluation or undervaluation depends on the true valuation. Let $\bar{y}$ and $\underline{y}$ be given by:

$$
\begin{gathered}
\bar{y}(y)=\lambda y, \quad \forall \lambda>1 . \\
\underline{y}(y)=\beta y, \quad \forall 0<\beta<1 .
\end{gathered}
$$

We assume that higher values of $y$ reflect more taxation on citizens. In case the public official, as an assessor, reports $\bar{y}$, the taxpayer has the right to approach a court of law and appeal against the assessment. But there is a cost of doing so. The costs of proving that the right valuation is $y$ instead of $\bar{y}$ is given by:

$$
C(y)=\alpha_{0}+\alpha_{1} y .
$$

$C(y)$ contains a fixed part $\alpha_{0}$ which suggests that no matter what the value of $y$ is, for example, one has to run-around and make a certain number of trips to the appellate authorities. Instead $\alpha_{1} y$ says that depending on $y$, certain fees need to be paid to the legal expert fighting for the plaintiff. Even if some costs are reimbursed, there is always a net cost.

Definition 1. Consider a proportional tax rate, $\tau>0$, on the true individual income, $y$, which cannot be misreported to the authorities (for instance formal wages, public and private salaries, shareholders, bank accounts, etc.). An 'honest' system is when $y(1-\tau)$ is the individual net pay-off.

Note that in case $\bar{y}$ is reported, a citizen would go to the court iff the following holds,

$$
y-\tau y-\alpha_{0}-\alpha_{1} y>y-\tau \lambda y
$$

or,

$$
y>\frac{\alpha_{0}}{\tau(\lambda-1)-\alpha_{1}} .
$$

Which says that the benefit of getting a court-verdict must outweigh the cost of doing so. Let

$$
\tilde{y}=\frac{\alpha_{0}}{\tau(\lambda-1)-\alpha_{1}}>0 .
$$

So, $\forall y>\bar{y}$, the taxpayer will go to the court and its reservation pay-off would be $\left[y(1-\tau)-\left(\alpha_{0}+\alpha_{1} y\right)\right]$. Similarly $\forall y \leq \bar{y}$, the taxpayer citizen will not go to the court and its reservation pay-off would be $(y-\tau \lambda y)$. Notice that if someone is indifferent between the two, he chooses not to go to the court. As we mentioned there is perfect information about individual income by part of official agents. Hence public officials know these reservation pay-offs for these two groups of taxpayers, the richest one, $R$, and the poorest one, $P$. Let us define these pay-offs as

$$
R \equiv\left[y(1-\tau)-\left(\alpha_{0}+\alpha_{1} y\right)\right], \quad \forall y>\bar{y}
$$


and

$$
P \equiv(y-\tau \lambda y), \quad \forall y \leq \bar{y} .
$$

The public official is corrupt and behaves in the following way. He/She would like a bribe for announcing $y$. But if the taxpayer insists on $y$ instead, then the corrupt official intimidate him, and so $\bar{y}$ will be assessed. Basically, the public official wants a share of $S_{R}>0$ from citizen $R$ and of $S_{P}>0$ from $P$ as a bribe, where $S_{R}$ and $S_{P}$ are defined by:

$$
S_{R}=y-\tau \beta y-R
$$

and,

$$
S_{P}=y-\tau \beta y-P .
$$

Let us assume that some bargaining power yields $\sigma S_{R}$ and $\sigma S_{P}$ to the public official, $0<\sigma<1$, i.e. it is the bargaining power or how much power corrupt officials have to take over for appropriating some part of the wealth of the people.

Therefore, the net pay-off to $R$ and $P$ citizens are,

$$
\Pi_{R}=y-\tau \beta y-\sigma S_{R}
$$

and,

$$
\Pi_{P}=y-\tau \beta y-\sigma S_{P} .
$$

We are now in a position to compare $\Pi_{R}$ and $\Pi_{P}$ with $y(1-\tau)$, the net pay-off in a honest system (Definition 1). That is,

$$
\Pi_{R}-y(1-\tau)=\tau y(1-\beta)-\sigma\left[\tau y(1-\beta)+\left(\alpha_{0}+\alpha_{1} y\right)\right],
$$

hence:

$$
\Pi_{R}>y(1-\tau) \Longleftrightarrow \sigma<\frac{\tau y(1-\beta)}{\tau y(1-\beta)+\left(\alpha_{0}+\alpha_{1} y\right)},
$$

and:

$$
\Pi_{P}-y(1-\tau)=\tau y(1-\beta)-\sigma \tau y(\lambda-\beta)
$$

hence:

$$
\Pi_{P}>y(1-\tau) \Longleftrightarrow \sigma<\frac{1-\beta}{\lambda-\beta}
$$

What (9) and (10) show, is to indicate how people with varying levels of income (or imputed income), threatened by the corruption of officials under a bribery behavior, compare their position vis-a-vis the honest system versus the "corrupt-system". Let us state the following proposition.

Proposition 1. Rich and poor citizens prefer an honest system or a corrupt system based on:

- For $\sigma \leq\left(\frac{1-\beta}{\lambda-\beta}\right)$, everyone prefers the corrupt system to the honest system.

- For $\sigma \in\left(\frac{(1-\beta)}{(\lambda-\beta)}, \frac{\tau(1-\beta)}{\tau(1-\beta)+\alpha_{1}}\right) \exists y^{*}>\tilde{y}$ such that people with $y<y^{*}$ prefer the honest system to the corrupt state and people with $y>y^{*}$, prefer the corrupt system to the honest system.

- For $\sigma \in\left[\frac{\tau(1-\beta)}{\tau(1-\beta)+\alpha_{1}}, 1\right]$, everyone prefers the honest system.

Proof. Let us prove the above statement for each item. 
- If $\sigma \leq\left(\frac{1-\beta}{\lambda-\beta}\right)$, from condition (10) it is obvious that $\forall y \leq \tilde{y}$, corrupt system will be preferred, since $\forall y>\tilde{y}$, we get that:

$$
\frac{\tau(1-\beta)}{\tau(1-\beta)+\alpha_{0} / y+\alpha_{1}}>\frac{(1-\beta)}{(\lambda-\beta)},
$$

and then everyone will prefer the corrupt system.

- Note that as $y \rightarrow \infty$, the RHS of (9), i.e. $\frac{\tau(1-\beta)}{\tau(1-\beta)+\alpha_{0} / y+\alpha_{1}}$ tends to $\frac{\tau(1-\beta)}{\tau(1-\beta)+\alpha_{1}}$. If $\frac{(1-\beta)}{(\lambda-\beta)}<\sigma<\frac{\tau(1-\beta)}{\tau(1-\beta)+\alpha_{1}}$ exists $y^{*}$ such that $\frac{\tau(1-\beta)}{\tau(1-\beta)+\alpha_{0} / y+\alpha_{1}}=\sigma$, where $y^{*}>\tilde{y}$. Hence for all $y \leq y^{*}$ people will prefer the honest system, whereas for $y>y^{*}$, people will prefer the corrupt system.

- Here, along with (9), (10) is reversed for all possible $y$. Therefore, everyone prefers the honest system.

Thus it has been demonstrated.

Corollary 1. Thus the richer section may prefer a corrupt system compared to the one where the public official behaves honestly.

Notice that, in the general case with given $\alpha_{0}>0, \alpha_{1}>0$, people with very high $y$, if corrupted by public officials, will go to the court and gets $y(1-\tau)-\left(\alpha_{0}+\alpha_{1} y\right)$. But he $\backslash$ she can share a surplus $\tau y(1-\beta)+\left(\alpha_{0}+\alpha_{1} y\right)$ with corrupt officials. So, unless $\sigma$ is high enough, his $\backslash$ her net pay-off is greater than $y(1-\tau)$ which he $\backslash$ she gets in the 'honest' system. So he $\backslash$ she prefers the corrupt system. However, this depends on the magnitude of $\alpha_{1}$ and $\sigma$. If $\alpha_{1}=0$, there is no $\sigma<1$ for which everyone prefers the honest system. Moreover, for the same $\sigma>\frac{(1-\beta)}{(\lambda-\beta)}$, critical $y^{*}$ will go down.

For richer people, the costs for corrupt behavior are relatively low and the average cost for facing corruption goes down with the level of income as there is a fixed cost. Hence, the richer section has a stronger bargaining power while sharing the benefit of underreported income relative to those who are poor and face relatively high costs for facing corruption.

\section{Corrupt Behavior of Taxpayers}

Let us analyze the other side of the coin, that is when taxpayers cheat in terms of their true income and thus try to evade taxes. As before, every citizen has a true income $y_{i}$, but now he $\backslash$ she cheats and declares an income $y_{i}^{*} \leq y_{i}$ after each tax period. Once again, the total set of taxpayers is divided into the groups of lowlevel income agents, the poor, and high-level income agents, the rich. Note that the number of partitions can be increased, but it does not affect the following arguments and conclusions.

For every taxpayer $i$, their incomes can take only two values: $y_{i} \in\{P, R\}$, where $P$ is the poor citizen or low-level income agent and $R$ is the rich citizen or high-level income agent $(0 \leq P<R)$. Declared (false, cheated) income $y_{i}^{*}$ also can take values from the mentioned binary set $y_{i}^{*} \in\{P, R\}$. Thus, in this model there are three different strategies $y_{i}^{*}\left(y_{i}\right)$, which depend on the relation between true and declared incomes:

1. $y_{i}^{*}\left(y_{i}\right)=P(P)$; 
2. $y_{i}^{*}\left(y_{i}\right)=R(R)$;

3. $y_{i}^{*}\left(y_{i}\right)=P(R)$.

Obviously that the taxpayers from the first and the second groups declare their income correspondingly to its true level and they do not intend to evade. The third group is the group of tax evaders.

Those rich citizens who declare themselves as poor, hence this group is of interest to the tax authority. The tax authority audits those taxpayers, who declared $y_{i}^{*}\left(y_{i}\right)=P$, with the probability $T_{P} \in[0,1]$ in every tax period.

Let's suppose that tax audit is absolutely effective, i. e. it reveals the existing evasion. Once the tax evasion is revealed, the evader must pay $(\tau+\mu)\left(y_{i}-y_{i}^{*}\right)>0$, where positive constants $\tau$ and $\mu$ are the tax and the penalty rates correspondingly, and $\left(y_{i}-y_{i}^{*}\right)$ is the hidden income. For the agents from the studied groups the payoffs are given by:

$$
\begin{gathered}
\pi(P(P))=(1-\tau) P \\
\pi(R(R))=(1-\tau) R \\
\pi(P(R))=R-\tau P-T_{P}(\tau+\mu)(R-P) .
\end{gathered}
$$

The tax authority gets information about taxpayers' incomes from their tax declarations and audits those, who declared $y_{i}^{*}=P$. The fraction of audited taxpayers is $T_{P}$. It's obvious that either the agents from the first group (who have true income $y_{i}=P$ ) or the evaders from the third group are both in this fraction of audited taxpayers.

The total set of the taxpayers is divided into the following groups: wealthy taxpayers, who pay taxes honestly $\left(y_{i}^{*}\left(y_{i}\right)=R(R)\right)$, insolvent taxpayers $\left(y_{i}^{*}\left(y_{i}\right)=\right.$ $P(P))$ and wealthy evaders $\left.\left(y_{i}^{*}\left(y_{i}\right)\right)=P(R)\right)$.

Hence, the following arguments, related to the searching of possible tax evasions, apply to the third group of the agents, declared $y_{i}^{*}\left(y_{i}\right)=P(R)$. The following proposition is straightforward.

Proposition 2. If taxpayers are risk-neutral, then the optimal value of audit probability depends on taxes, $\tau$, and inversely on the penalty rate, $\mu$.

Proof. Risk-neutral taxpayers' behavior supposed to be rational, i.e. their tax evasion is impossible only if the risk of punishment is so high that the tax evader's profit is less or equal to his $\backslash$ her expected post-audit payments (in the case when his evasion is revealed), then:

$$
T_{P}(\tau+\mu)(R-P) \geq \tau(R-P) .
$$

Therefore, the critical value of audit probability $T_{P}$ (due to the taxpayer's decision to evade or not) is

$$
T_{P}^{*}=\frac{\tau}{\tau+\mu} .
$$

For this type of models the optimal solution is usually presented in the form of the "threshold rule" in various modifications (see, for example, (Chander and Wilde, 1998) or (Vasin and Morozov, 2005)). In (Boure and Kumacheva, 2010) this rule is formulated so that the optimal value $T_{P}^{*}$ of the auditing probability is defined from (14), and for the risk neutral taxpayer the optimal strategy is

$$
y_{i}^{*}\left(y_{i}\right)=\left\{\begin{array}{l}
R, T_{P} \geq T_{P}^{*} \\
P, T_{P}<T_{P}^{*}
\end{array}\right.
$$


In our study we assume that people from risk-loving and risk-averse subgroups keep their behavior despite of received information. It means that the value of collected taxes does not depend on these groups, whereas risk-neutral agents react on the received information and can change their behavior. For example if a risk-neutral agent receives information that probability of tax audit is high then he $\backslash$ she pays taxes honestly, else he $\backslash$ she evades.

We assume that information can be disseminated through social networks. We may consider it as a "stochastic alarm" (see Sandholm, 2010), which means the signal to agent that he $\backslash$ she has an opportunity to react to the changes in the environment. Nevertheless, some problems should be fixed to make the static model described above close to the real-life process. The first problem is that the players are supposed to be risk-neutral. However, in real life, there are also risk-averse and risk-loving economic agents. Another problem is that we consider the game with complete information. It is assumed that the taxpayers know (or can estimate) the value of the auditing probability, but in the current study, we do not take into account the method of receiving information. Another problem is that the auditing with optimal probability (11) is excessively expensive and the tax authority usually has a strongly limited budget, thus the actual value of $T_{P}$ should be substantially less than $T_{P}^{*}$ in real life. By taking into consideration all mentioned reasons, in what follows, we formulate an extended model of tax auditing which includes an information component and an evolutionary process of adaptation of the population of taxpayers to changes in the economic environment.

\section{Evolutionary Games, Networks and Tax Collection}

In this section, we introduce the formulation of an evolutionary model of information spreading over the population of taxpayers. In a real-life situation, agents who received information will share it with their closest neighbors, such as family, friends, and colleagues. Hence it is more natural to consider a population with a network structure in formalization of evolutionary game. The main difference from the classical evolutionary game is that here agents transfer information, not to a random opponent but they communicate only with connected neighbors and friends. The paper discusses three methods of selecting neighbors in the terms network topology. The first method a grid is used to define the links between taxpayers. The second network structure is a strongly connected network, and the third network structure a weakly connected network.

Let $G=(N, L)$ denote an indirect network, where $N=\{1, \ldots, n\}$ is a set of economic agent and $L \subset N \times N$ is an edge set. Each edge in $L$ represents two-player symmetric game between connected taxpayers. The taxpayers choose strategies from a binary set $X=$ \{to pay taxes, to evade taxes $\}$ and receive payoffs according to a matrix of payoff. Each instant time moment agents use a single strategy against all opponents and thus the games occurs simultaneously. We denote the strategy state by the vector $x(t)=\left(x_{1}(t), \ldots, x_{n}(t)\right)^{T}, x_{i}(t) \in X$ (T is a transpose sign). Here $x_{i}(t) \in X$ is a strategy of taxpayer $i, i=\overline{1, n}$, at time moment $t$. The detailed definition of the games will be presented in subsection 4.1. Aggregated payoff of agent $i$ can be defined as in Riehl and Cao (2015), i.e.

$$
\pi_{i}=\omega_{i} \sum_{j \in M_{i}} a_{x_{i}(t), x_{j}(t)},
$$


where $a_{x_{i}(t), x_{j}(t)}$ is a component of payoff matrix, $M_{i}:=\{j \in L:\{i, j\} \in L\}$ is a set of neighbors for taxpayer $i$, weighted coefficient $\omega_{i}=1$ for cumulative payoffs and $\omega_{i}=\frac{1}{\left|M_{i}\right|}$ for averaged payoffs. Vector of payoffs of the total population is $\pi(t)=\left(\pi_{1}(t), \ldots, \pi_{n}(t)\right)^{T}$.

The state of population will be changed according to the rule, which is a function of the strategies and payoffs of neighboring agents:

$$
x_{i}(t+1)=f\left(\left\{x_{j}(t), \pi_{j}(t): j \in M_{i} \cup\{i\}\right\}\right) .
$$

Here we suppose that taxpayer changes his $\backslash$ her behavior if at least one neighbor has better payoff. As the example of such dynamics we can use the proportional imitation rule (Sandholm, 2010), in which each agent chooses a neighbor randomly and if this neighbor received a higher payoff by using a different strategy, then the agent will switch with a probability proportional to the payoff difference. The proportional imitation rule can be presented as:

$$
p\left(x_{i}(t+1)=x_{j}(t)\right):=\left[\frac{\lambda}{\left|M_{i}\right|}\left(\pi_{j}(t)-\pi_{i}(t)\right)\right]_{0}^{1}
$$

for each agent $i \in L$ where $j \in M_{i}$ is a uniformly randomly chosen neighbor, $\lambda>0$ is an arbitrary rate constant, and the notation $[z]_{0}^{1}$ indicates $\max (0, \min (1, z))$.

\subsection{An Instant Game}

As in classical evolutionary game theory, the instant communications between taxpayers is described by two players bimatrix game. We denote by $A$ a matrix for the first player and the payoff matrix for her opponent by $B=A^{T}$. The next modified payoff matrix is adapted to the model of tax control.

Remark 1. Corruption and evasion of taxation can be analyzed as baseline games, i.e. i) prisoner's dilemma game, ii) stag hunt game, and iii) hawk-dove game. Whereas total tax revenue depends on information regarding the tax control system.

The current subsection examines an instant game between a couple of taxpayers in a structured population. As it was shown in (Sandholm, 2010; Weibull, 1995) the instant interactions between taxpayers can be defined by two-players symmetric bimatrix game $\Gamma(A, B)$. There are exist four classes of two-players symmetric bimatrix games, where each class is characterized by the structure of the game, general properties of strategies, and equilibrium profiles. Below we present the three types of such bimatrix games in terms of tax-control system and use their structures as a possible scenario of the interaction between two agents in the process of the dissemination of information.

Since the structure of the strategies sets and payoff functions are the same in this class of games then the payoff matrix for the first player is denoted as $A$ and for the second player, payoff matrix is defined as $B=A^{T}$. According to this notation, in tables below strategies and payoffs of the first player are represented to simplify the visual presentation. In our study, we suppose that the payoff matrix of the instant game between connected agents has the structure of one of the following classical games: the Prisoner's Dilemma, the Stag Hunt game, the Hawk-Dove game. Since the structure of these bimatrix games is well-known, they are appropriated to evaluate the impact of network structure and imitation rules. Further, an instant interaction can be modeled by using the special structure of the game. 
The Prisoner's Dilemma Firstly, we modify the Prisoner's Dilemma in terms of tax-control:

$$
\begin{array}{c|cc} 
& C & D \\
\hline C & \bar{\pi}+S W & \bar{\pi}-S W \\
D & \pi(L(H)) & \bar{\pi}
\end{array}
$$

where strategy $C$ is "to cooperate" and can be interpreted as behavior "to pay taxes". Strategy $D$ corresponds to behavior "to defect" in the classical formulation, but in our interpretation, it describes behavior to evade. The second player uses the same strategy set $\{C, D\}$. Payoff

$$
\bar{\pi}=1 / 2 \pi(P(P))+1 / 2 \pi(R(R))
$$

is an average profit of the "mean" agent, parameter $S W>0$ defines social welfare, obtained for the participation in social consolidation, which means that if taxpayers pay taxes then he $\backslash$ she receives some social goods provided by the collected taxes.

The Stag Hunt game. Since this bimatrix game describes a social choice between personal and public goods then we choose it as an alternative instant game between connected taxpayers. Here payoff matrix for the first player is

\begin{tabular}{c|cc} 
& $S$ & $H$ \\
\hline$S$ & $\bar{\pi}+S W$ & 0 \\
$H$ & $\bar{\pi}-S W$ & $\bar{\pi}-S W$
\end{tabular}

where we can interpret player's strategies in the following way: strategy $S$ and $H$ correspond to hunt and a hare in the classical case. The second player uses the same strategy set $\{S, H\}$. In our framework strategy, $S$ defines honest behavior and dictates taxpayers to pay taxes and strategy $H$ fits to evasion respectively.

The Hawk-Dove game. As the third alternative of the instant game we use the Hawk-Dove game, which also describes a conflict between more and less aggressive players. As in previous cases, we define a payoff matrix for the first player as:

\begin{tabular}{c|cc} 
& $H$ & $D$ \\
\hline$H$ & $\frac{\pi(P(R))-(\tau+\mu)(R-P)}{2}$ & $\pi+S W$ \\
$D$ & 0 & $\frac{\pi+S W}{2}$
\end{tabular}

where strategy $H$ corresponds to Hawk, behaves aggressively, in our framework it defines the behavior to evade taxation. Strategy $D$ corresponds to be a Dove, who behaves passive, and in our formulation, this strategy defined the honest behavior and player pays taxes. The second player uses the same strategy set $\{H, D\}$. Here we suppose that individual payoffs satisfy the inequality $\pi(P(R))<<(\tau+\mu)(R-P)$, which means that it is appropriate for the large values of parameters $\tau$ and $\mu$, when there is a big difference $(R-P)$.

\subsection{Total Tax Revenue}

We use the next assumptions to describe the aggregated system costs which occur during the process of information spreading over the population of taxpayers: 
- The considered population is restricted by the subpopulation of rich taxpayers $R$ with high level of income, where $n_{R}$ is a number of agents in population;

- If there is no information circulates in the populations then the total population evades hence $n_{R}=n_{e v}$, where $n_{e v}$ is the number of evaders);

- If information is injected in the initial time moment by the tax authority then we denote by $n_{\text {inf }}^{0}=n_{n e v}^{0}$ the number of informed taxpayers about increased probability of tax auditing and then they decided not to evade;

- In each time moment we have $n_{R}=n_{e v}(t)+n_{\text {nev }}(t)\left(\right.$ or $\left.\nu_{n e v}(t)+\nu_{e v}(t)=1\right)$, $t \in[0, T]$, where $T$ is the time of information injection.

Based on these assumptions we can state the following corollary.

Corollary 2. There are two different types of models for tax control. The first model does not include the process of information dissemination. If the information does not circulate in the population then risk-neutral taxpayers do not pay taxes. Also if taxpayers suppose that the probability of auditing is rather small $\left(T_{p}<T_{p}^{*}\right)$, then they also evade and the only honest taxpayers are risk-averse agents.

Hence, we can compute the total tax revenue in case of the absence of information, i.e.

$$
T T R_{0}=n_{P} \tau P+n_{R}\left(\tau P+T_{P}(\tau+\mu)(R-P)\right)-n T_{P} c .
$$

If we take into account the dissemination of information in the population of taxpayers then at the initial moment tax control system injects information into the population. Since information starts to circulate in population then we have a share of informed taxpayers $\nu_{i n f}^{0}=\nu_{i n f}\left(t_{0}\right)$. The cost of unit of information is $c_{\text {inf }}\left(c_{\text {inf }}<<c\right)$. At the moment when the system reached its steady state $\nu_{\text {inf }}$ is the share of those who perceived information and paid taxes, $\nu_{e v}$ is the share of those who still evades. In this case the total tax revenue is

$$
\begin{aligned}
T T R_{T}=n_{P} \tau P+n_{R} & \left(\nu_{n e v}^{T} \tau R+\nu_{e v}^{T}\left(\tau P+T_{P}(\tau+\mu)(R-P)\right)\right)- \\
& -n\left(T_{P} c+\nu_{i n f}^{0} c_{i n f}\right),
\end{aligned}
$$

where $\nu_{n e v}^{T}$ is the share of taxpayers who don't evade at the moment $t=T, \nu_{e v}^{T}$ is the share of taxpayers who continue to evade taxation at the moment $t=T$, $\nu_{i n f}^{0}$ is the value (fraction) of the informational injection at the initial time moment $\left(\nu_{\text {inf }}^{0}=\nu_{\text {inf }}\left(t_{0}\right)\right)$.

In the following section, we present a simulation analysis on dynamic networks to verify the aforementioned about the control of tax collection, considering: i) tax and penalty rates, ii) probabilities and costs of auditing, iii) the information levels, and so iv) looking at the network's dynamics of the share of tax evaders citizens.

\section{Numerical Simulations}

In this section we represent the series of numerical experiments to illustrate evolution of the behaviors in the population of taxpayers in the long-run period and estimate the impact of information propagation on the desire of evasion. By using the model of information spreading, we run experiments for different cases of the network topology and instant games. All experiments include a grid, strongly and weakly connected random graphs. 
The evolutionary process of spreading information in the population of taxpayers is based on the instant bimatrix games such as the Prisoner's Dilemma, Stag Hunt, Hawk, and Dove games to define the interconnections between taxpayers. The empirical data used in all experiments are based on the following values for tax and penalty rates (see. tabl. 1) and the distribution of incomes over the total population. The distribution of incomes has been taken from (The web-site of the Russian Federation State Statistics Service, 2018).

Table 1 contains values of general parameters of the model. Subsection 5.1. shows the selected experiments, which reflect the most interesting cases of the system evolution, which demonstrate the facilities of the specially designed software. Multiple running of the script enables to assess the trends in the behavior of taxpayers and can serve as a basis for further development of the decision-making system.

The results of the iterative process of spreading information over the population of taxpayers were visualized on a small network of 25 nodes $\left(n_{R}=25\right)$, however, all these results can be extended for a large number of nodes. According to the formula of total tax revenue (19) we calculate total tax revenue, which is $T T R_{0}=56855.81$ rub in each experiment. In all figures the identical notation is used to define the nodes in the networks: we mark the agents who use strategy "to pay taxes" as yellow dots and the agents who use strategy "to evade" as the blue dots. Series of numerical simulations have been split into several series of experiments subject to the network configuration. The results of different runs of specially developed software are summarized in tables 3-6. In all tables the next notations are used: PD corresponds to the Prisoners Dilemma game, HD corresponds to the HawkDove game, SH corresponds to the Stag Hunt game.

Table 1. General parameters for numerical simulations.

\begin{tabular}{c|c}
\hline Parameter & Value \\
\hline tax rate & $\tau=13 \%$ \\
penalty rate & $\mu=13 \%$ \\
optimal value of the probability of audit & $T_{P}^{*}=0.5$ \\
actual value of the probabilities of audit & $T_{P}=0.1$ \\
unit cost of auditing & $c=7455$ (rub.) \\
unit cost of information injection & $c_{i n f}=10 \% c=745.5($ rub.) \\
stopping point of the iteration process & $\sqrt{\sum_{i=1}^{n}\left(x_{i}(t)-x_{i}(t+1)\right) \leq 10^{-3}}$ \\
\hline
\end{tabular}

The distribution of the income among the population of the Russian Federation in 2018 (see Tab. 2).

\subsection{Experiments}

Series 1: Grid. This paragraph represents the results of numerical experiments on the network of the grid and different structures of bimatrix games. Table 3 collects some auxiliary information of the experiments: type of the instant game, initial and final states, etc. 
Table 2. Two modeled groups and average income

\begin{tabular}{llll}
\hline group & $\begin{array}{l}\text { income } \\
\text { (rub./month) }\end{array}$ & $\begin{array}{l}\text { interval } \\
\text { (rub.) }\end{array}$ & $\begin{array}{l}\text { income } \\
(\%)\end{array}$ \\
\hline$P$ & less 25000 & $P=12500$ & 43 \\
$R$ & more 25000 & $R=50000$ & 57 \\
\hline
\end{tabular}

Table 3. Results of Simulation for Grid

\begin{tabular}{ccccccc}
\hline $\begin{array}{c}\text { Num- Initial injection } \\
\text { ber } \\
\text { of information } \\
\nu_{i n f}^{0}\end{array}$ & $\begin{array}{c}\text { Initial } \\
\text { state } \\
\left(n_{n e v}^{0}, n_{e v}^{0}\right)\end{array}$ & $\begin{array}{c}\text { Payoff } \\
\text { matrix }\end{array}$ & $\begin{array}{c}\text { Number of } \\
\text { iterations }\end{array}$ & $\begin{array}{c}\text { Final } \\
\text { state } \\
\left(n_{n e v}^{T}, n_{e v}^{T}\right)\end{array}$ & $\begin{array}{c}\text { The value } \\
\text { of } T T R_{T} \\
(\mathbf{r u b})\end{array}$ \\
\hline 1 & 15 & $(15,10)$ & PD & 6 & $(0,25)$ & 24071.12 \\
\hline 2 & 11 & $(11,14)$ & SH & 2 & $(11,14)$ & 49306.94 \\
\hline 3 & 4 & $(4,21)$ & HD & 25 & $(25,0)$ & 87592.56 \\
\hline
\end{tabular}

In the current experiment, we can notice that if the interaction between taxpayers is defined by the Stag Hunt game, then the number of non-evaders and, therefore, the total tax revenue is increasing.

Figures $1-3$ illustrate the evolution of the taxpayers preferences during the long-time period. In all experiments pairs of figures demonstrate the proportions of evaders $n_{e v}$ and non-evaders $n_{n e v}$ taxpayers in population in the initial and final time moments.

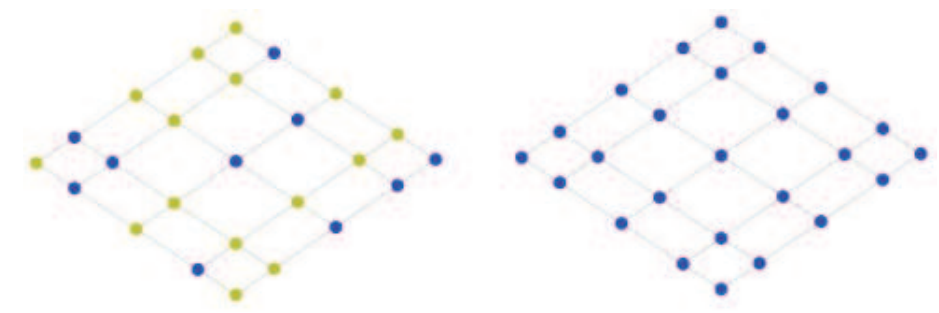

Fig. 1. Initial state: $\left(n_{n e v}, n_{e v}\right)=(15,10)$; final state: $\left(n_{n e v}, n_{e v}\right)=(0,25)$.

Series 2: Random Graph. The current series of numerical experiments represent results for the case of the random graph. Table 4 collects some auxiliary information of the experiment.

This series of experiments demonstrates the effectiveness of the Hawk-Dove game structure amongst the others. In this scheme, the number of non-evaders is increasing, and therefore we have $T T R_{T}>T T R_{0}$.

Fig. 4 illustrates the changes in taxpayers' behavior in the initial and final time moments. 


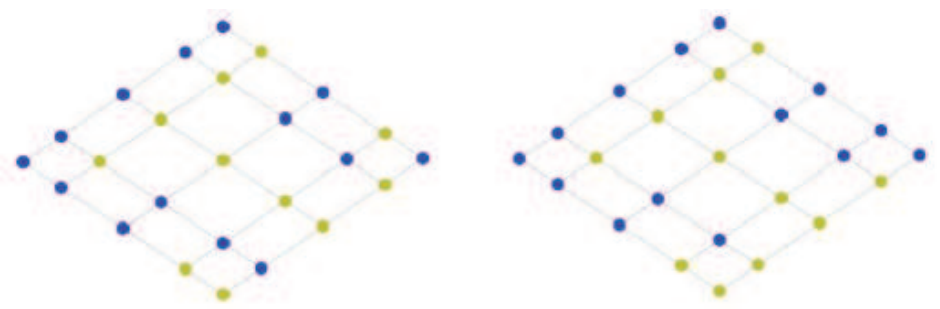

Fig. 2. Initial state: $\left(n_{\text {nev }}, n_{e v}\right)=(11,14)$; final state: $\left(n_{n e v}, n_{e v}\right)=(11,14)$.
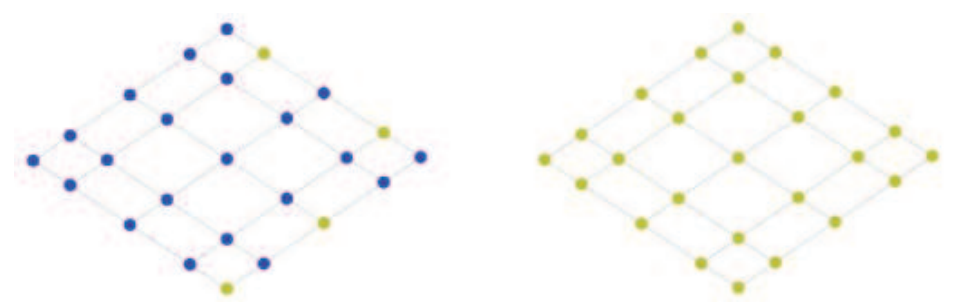

Fig. 3. Initial state: $\left(n_{n e v}, n_{e v}\right)=(4,21)$; final state: $\left(n_{n e v}, n_{e v}\right)=(25,0)$.

Table 4. Results of Simulation for Random Graph

\begin{tabular}{ccccccc}
\hline $\begin{array}{c}\text { Num- Initial injection } \\
\text { ber } \\
\text { of information } \\
\nu_{i n f}^{0}\end{array}$ & $\begin{array}{c}\text { Initial } \\
\text { state } \\
\left(n_{n e v}^{0}, n_{e v}^{0}\right)\end{array}$ & $\begin{array}{c}\text { Payoff } \\
\text { matrix }\end{array}$ & $\begin{array}{c}\text { Number of } \\
\text { iterations }\end{array}$ & $\begin{array}{c}\text { Final } \\
\text { state } \\
\left(n_{n e v}^{T}, n_{e v}^{T}\right)\end{array}$ & $\begin{array}{c}\text { The value } \\
\text { of } T T R_{T} \\
(\mathbf{r u b})\end{array}$ \\
\hline 1 & 4 & $(4,21)$ & HD & 18 & $(25,0)$ & 87592.56 \\
\hline
\end{tabular}
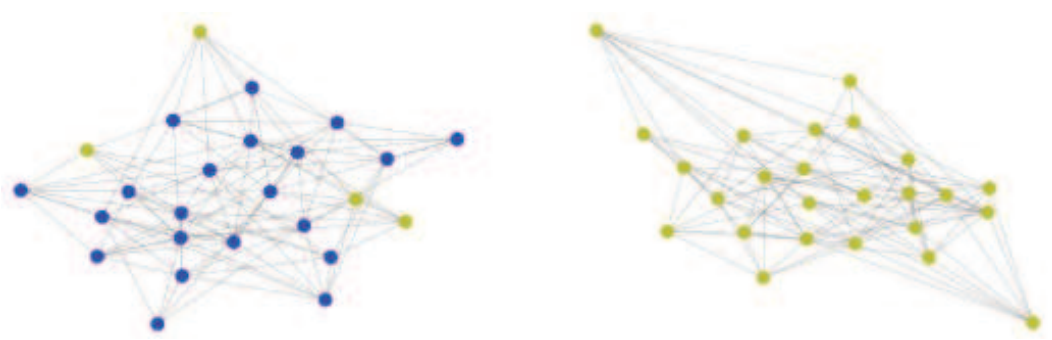

Fig. 4. Initial state: $\left(n_{n e v}, n_{e v}\right)=(4,21)$; final state: $\left(n_{n e v}, n_{e v}\right)=(25,0)$.

Series 3: Strongly Connected Network. This paragraph represents the results of experiments obtained for the strongly connected network. Tab. 5 collects additional information about numerical simulations.

In this case, the Prisoner's Dilemma seems to be the most effective in economic meaning.

Figs. $5-7$ illustrate the evolution of the taxpayers' behavior. 
Table 5. Results of Simulation for Strongly Connected Network

\begin{tabular}{ccccccc}
\hline $\begin{array}{c}\text { Num- Initial injection } \\
\text { ber } \\
\text { of information } \\
\nu_{i n f}^{0}\end{array}$ & $\begin{array}{c}\text { Initial } \\
\text { state } \\
\left(n_{n e v}^{0}, n_{e v}^{0}\right)\end{array}$ & $\begin{array}{c}\text { Payoff } \\
\text { matrix }\end{array}$ & $\begin{array}{c}\text { Number of } \\
\text { iterations }\end{array}$ & $\begin{array}{c}\text { Final } \\
\text { state } \\
\left(n_{n e v}^{T}, n_{e v}^{T}\right)\end{array}$ & $\begin{array}{c}\text { The value } \\
\text { of } T T R_{T} \\
(\mathbf{r u b})\end{array}$ \\
\hline 1 & 16 & $(16,9)$ & $\mathrm{PD}$ & 8 & $(0,25)$ & 19598.12 \\
\hline 2 & 13 & $(13,12)$ & $\mathrm{SH}$ & 7 & $(25,0)$ & 80883.06 \\
\hline 3 & 7 & $(7,18)$ & $\mathrm{HD}$ & 11 & $(22,3)$ & 78270.25 \\
\hline
\end{tabular}
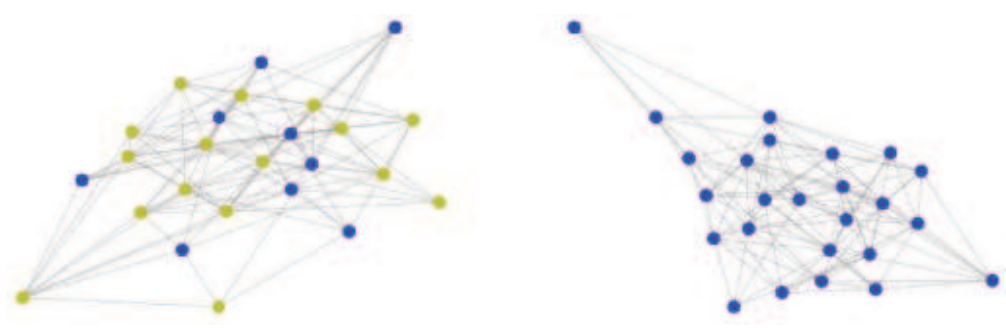

Fig. 5. Initial state: $\left(n_{n e v}, n_{e v}\right)=(16,9)$; final state: $\left(n_{n e v}, n_{e v}\right)=(0,25)$.
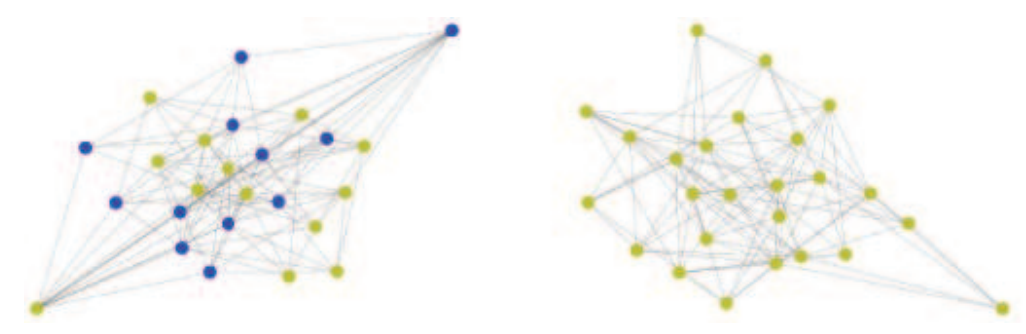

Fig. 6. Initial state: $\left(n_{n e v}, n_{e v}\right)=(13,12)$; final state: $\left(n_{n e v}, n_{e v}\right)=(25,0)$.
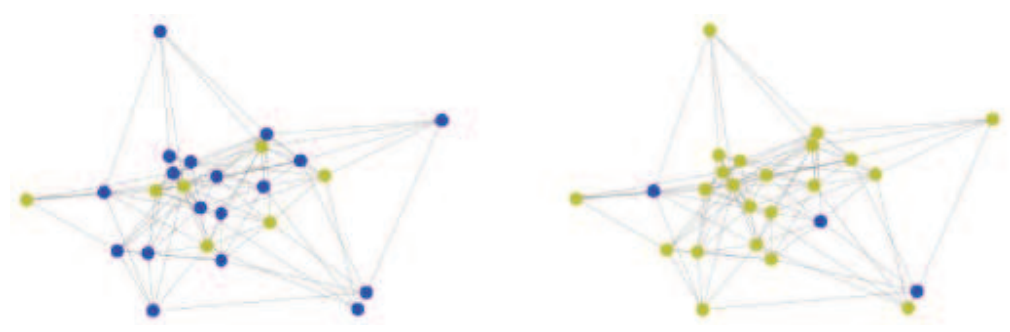

Fig. 7. Initial state: $\left(n_{n e v}, n_{e v}\right)=(7,18)$; final state: $\left(n_{n e v}, n_{e v}\right)=(22,3)$.

Series 4: Weakly Connected Network. The results of experiments for the weakly connected network are summarized and presented in the Tab. 6 . 
Table 6. Results of Simulation for Weakly Connected Network

\begin{tabular}{ccccccc}
\hline $\begin{array}{c}\text { Num- Initial injection } \\
\text { ber } \\
\text { of information } \\
\nu_{i n f}^{0}\end{array}$ & $\begin{array}{c}\text { Initial } \\
\text { state } \\
\left(n_{n e v}^{0}, n_{e v}^{0}\right)\end{array}$ & $\begin{array}{c}\text { Payoff } \\
\text { matrix }\end{array}$ & $\begin{array}{c}\text { Number of } \\
\text { iterations }\end{array}$ & $\begin{array}{c}\text { Final } \\
\text { state } \\
\left(n_{n e v}^{T}, n_{e v}^{T}\right)\end{array}$ & $\begin{array}{c}\text { The value } \\
\text { of } T T R_{T} \\
\text { (rub) }\end{array}$ \\
\hline 1 & 14 & $(14,11)$ & SH & 4 & $(20,5)$ & 68327.87 \\
\hline 2 & 4 & $(4,21)$ & HD & 6 & $(16,9)$ & 66335.12 \\
\hline
\end{tabular}

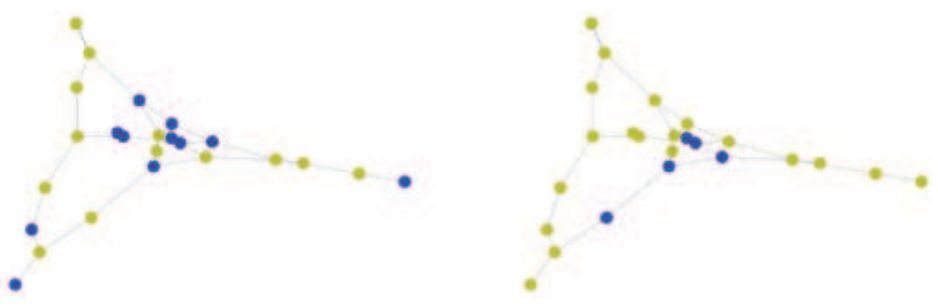

Fig. 8. Initial state: $\left(n_{n e v}, n_{e v}\right)=(14,11)$; final state: $\left(n_{n e v}, n_{e v}\right)=(20,5)$.
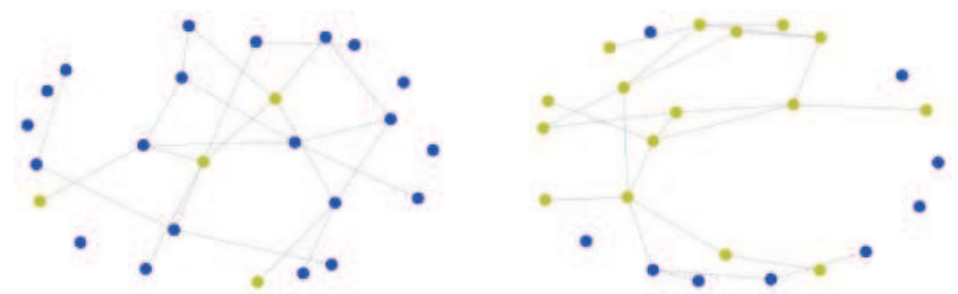

Fig. 9. Initial state: $\left(n_{n e v}, n_{e v}\right)=(4,21)$; final state: $\left(n_{n e v}, n_{e v}\right)=(16,9)$.

The main result of the experiments is that the information spreading is noneffective for the weakly connected network in both game structures: the Stag Hunt and the Hawk-Dove games.

Figs. $8-9$ illustrate evolution of the system under information spreading.

\subsection{Numerical Simulations: the Main Trends and Discussion}

The series of numerical experiments show that the final distribution of taxpayers between honest and evaders depends on some reasons. We receive that network structure and an instant game between connected taxpayers strongly influence the final state. In our simulation, we have that if we choose the Prisoner's Dilemma as an instant game then due to the properties of this game, evaders, which strategy corresponds to strategy $D$ prevail. That means that the equilibrium is achieved in the case when both interacting agents choose a strategy of tax evasion. If we use the Stag Hunt game as a game between connected taxpayers then we have several subcases: 
- If we calculate cumulative and average payoffs with a uniform initial distribution of strategies then in the steady-state the honest taxpayers prevail.

- However we receive that both mixed equilibria are possible, as well as situations where all taxpayers at the final moment shy away or not evade taxes.

For the Hawk-Dove game as an instant game, we have that mixed equilibrium or equilibrium of non-evaders prevail. There is a positive trend from the fiscal authorities' point of view: the increase in the number of non-evading agents.

Additionally, it can be noticed that the final distribution of taxpayers in an iterative process of information spreading depends on the number of iterations, the existence of isolated groups of taxpayers who are not involved in propagation process; the initial injection of the information (the share of those who received the information); class of payoff matrix which influence on the structure of Nash equilibria.

As the main results of the series of numerical simulations we can see that the propagation information about possible tax audits over the papulation of taxpayers brings a positive effect for the total revenue of the fiscal system and increases the total amount of honest taxpayers. Knowledge of the structure of the payoff matrix simplifies the behavioral analysis of the impact of information on the effectiveness of tax control.

\section{Concluding Remarks}

Corruption on the part of the bureaucracy appears or operates in several ways, but above all in two directions: diversion of resources in non-existent firms; or in work contracts drafted and designed with the skill to economically favor one or both parties, i.e. the agreement between the government and private initiative at all levels. From this perspective, public expenditure, as an integral part of national income, is diverted and therefore only a small part of the population, in general, the richest is benefited, but above all, because as a positive multiplier effect of the economy, its application distorted that impact, reducing aggregate income and therefore aggregate demand, the domestic market. In the absence of efficiency in public administration, plus impunity between the parties involved in corruption, for the rich, it is easier to resort to bribery or collusion, both to reduce processing times and to conduct business with guaranteed profit. Although corruption is an important factor in the inequitable distribution of income, as the model demonstrates, and therefore a factor that can influence the reduced economic growth, although the streamlining of procedures through bribery could eventually boost business. However, inequality is one of the most visible effects of corruption.

In this research paper, we study the network's dynamics of agents with High and Low levels of income (Poor and Rich agents), where these two groups of agents differ by their relation to corruption on a tax payment system. It is known that audit of the whole population of taxpayers needs a large budget to catch taxpayers who prefer to evade taxes and reach an optimal value of audited subpopulation. However, usually, the tax authority has a limited budget and it is necessary to find additional methods to reach an optimal share of audited taxpayers.

Therefore, we have included the process of information spreading into an evolutionary model of tax control on the network. The evolutionary model helps to estimate the impact of information about a future tax audit, received from the tax authority on the decisions of taxpayers. We also reformulate classical bimatrix 
games in terms of the tax authority system to use them as instant games into the evolutionary process. Series of numerical simulations have shown that the final distribution of taxpayers who pay taxes depends on the network structure and received information. Hence propagation information about possible tax audits gives a positive effect on the total revenue of the fiscal system and increases the total amount of taxpayers who prefer to pay taxes honestly. The process of changes in taxpayers' behavior over time is presented by the complicated model we illustrate in numerical experiments.

Tax authorities disseminate information that they intend to verify no less than this proportion of the population. However, since the budget is not always such as to provide such an audit plan, this information, in particular, may turn out to be misinformation. But even in this case, it is economically efficient (increases tax collection), which we showed using our simulation modeling. All experiments were made under the assumption of full rationality of agents, which means that we take into account only risk-neutral agents, but in the future, it is possible to extend the model with risk-loving and risk-averse agents.

The current research shows that one of the most important aspects for restarting the momentum of economic growth and the distribution of wealth for development, among other strategies of effective economic policy, is to reduce corruption and, above all, to have effective control of the ability to collect taxes to apply a policy for the redistribution of income.

\section{References}

Abed, G., Davoodi, H. (2000). Corruption, Structural Reforms and Economic Performance in the Transition Economies. Washington: International Monetary Fund, IMF Working Paper, 132.

Accinelli, E., Sanchez Carrera, E. (2012). Corruption driven by imitative behavior. Economics Letters 117(1), 84-87.

Ades, A., Di Tella, R. (1997). The New Economics of Corruption: A Survey and some New Results. Political Studies, 45, 496-515.

Andres, A., Ramlogan-Dobson, C. (2011). Is Corruption Really Bad for Inequality? Evidence from Latin America. The Journal of Development Studies, 47(7), 959-976.

Akçay, S. (2006). Corruption and Human Development. Cato Journal, 26(1), 29-48.

Al-Marhubi, F. A. (2006). Corruption and Inflation. Economics Letters, 66, 199-202.

Antoci, A., Russua, P., Zarri, L. (2014). Tax Evasion in a Behaviorally Heterogeneous Society: An Evolutionary Analysis. Economic Modelling, 42, 106-115.

Antunes, L., Balsa, J., Urbano, P., Moniz, L., Roseta-Palma, C. (2006). Tax Compliance in a Simulated Heterogeneous Multi-agent Society. In: Sichman J.S., Antunes L. (eds) Multi-Agent-Based Simulation VI. MABS 2005. Lecture Notes in Computer Science, vol 3891, pp. 147-161. Springer, Berlin, Heidelberg

Apergis, N., Dincer, O., Payne, J. (2010). The relationship between corruption and income inequality in U.S. states: evidence from a panel cointegration and error correction model. Public Choice, 145, 125-135.

Bardhan, P. (1997). Corrutpion and development: a Review of Issues. Journal of Economic Literature, 35, 1320-1346.

Barro, R. J. (2000). Inequality and Growth in a Panel of Countries. Journal of Economic Growth, 5, 5-32.

Boure, V., Kumacheva, S. (2010). A game theory model of tax auditing using statistical information about taxpayers. Vestnik SPbGU, series 10, 4, 16-24 (in Russian).

Bloomquist, K. M. (2006). A comparison of agent-based models of income tax evasion. Social Science Computer Review, 24(4), 411-425. 
Champernowne, D. G. and F.A. Cowell (1998). Economic inequality and Income distribution. Cambridge University Press.

Chander, P., Wilde, L. (1998). A General Characterization of Optimal Income Tax Enforcement. Rev. of Econ. Studies., 65, 165-183.

Choi, I. (2001). Unit root tests for panel data. Journal of International Money and Finance, 20, 249-272.

Chong, A., Gradstein, M. (2007). Inequality and Institutions. The Review of Economics and Statistics, 89(3), 454-465.

Deaton, A. (2003). Health, Inequality and Economic Development. Journal of Economic Literature, 41(1), 113-158.

De Gregorio, J., Lee J. W. (2002). Education and Income Inequality: New Evidence from Cross-country Data. Review of Income and Wealth, 48, 395-416.

Dincer, O.C., Gunalp, B. (2005). Corruption, Income Inequality, and Growth: Evidence from U.S. States. SSRN Electronic Journal, SSRN Electron. J. http://dx.doi.org/10.2139/ssrn.690381.

Dumitrescu, E. and C. Hurlin (2012). Testing for Granger Non-causality in Heterogeneous Panels. Economic Modelling, 29, 1450-1460.

Ghura, D. (1998). Tax Revenue in Sub-Sharan Africa: Effects of Economic Policies and Corruption. IMF Working Paper. Washington: International Monetary Fund.

Gubar, E., Kumacheva, S., Zhitkova, E., Kurnosykh, Z. (2017). Evolutionary Behavior of Taxpayers in the Model of Information Dissemination. Constructive Nonsmooth Analysis and Related Topics (Dedicated to the Memory of V.F. Demyanov), CNSA 2017. Proceedings, IEEE Conference Publications. pp. 1-4.

Gubar, E., Kumacheva, S., Zhitkova, E., Kurnosykh, Z., Skovorodina, T. (2017). Modelling of Information Spreading in the Population of Taxpayers: Evolutionary Approach. Contributions to Game Theory and Management, 10, 100-128.

Gubar, E. A., Kumacheva, S.Sh., Zhitkova, E. M., Porokhnyavaya, O. Yu. (2015). Propagation of information over the network of taxpayers in the model of tax auditing. International Conference on Stability and Control Processes in Memory of V.I. Zubov, (SCP 2015). Proceedings, IEEE Conference Publications. INSPEC Accession Number: 15637330, pp. 244-247.

Gubar, E., Kumacheva, S., Zhitkova, E., \& Tomilina, G. (2019). Modeling of the impact of information on tax audits on the risk statuses and evasions of individuals. Vestnik SPbGU, 15(2), 245-258. (in Russian).

Gupta, S., Davoodi, H., Tiongson E. (2000). Corruption and the Provision of Health Care and Education Services. IMF Working Paper, 116. Washington: International Monetary Fund.

Gupta, S., Davoodi, H., Alonso-Terme, R. (2002). Does corruption affect income inequality and poverty? Economics of Governance, 3, 23-45.

Gymah-Brempong, K., (2002). Corruption, economic growth and income inequality in africa. Economics of Governance 3, 183 - 209.

Habib, M., Zurawicki, L. (2001). Country-Level Investments and the Effect of Corruption: Some Empirical Evidence. International Business Review, 10,687-700.

Im, K.S., Pesaran, M. H., Shin, Y. (2003). Testing for unit roots in heterogeneous panels. Journal of Econometric, 115, 53-74.

Kumacheva, S.Sh. (2012). Tax Auditing Using Statistical Information about Taxpayers. Contributions to Game Theory and Management, 5, 56-167.

Kumacheva, S. Sh., Gubar, E. A. (2015). Evolutionary model of tax auditing. Contributions to Game Theory and Management, 8, 164-175.

Kumacheva, S., Gubar, E., Zhitkova, E., Tomilina, G. (2018). Evolution of Risk-Statuses in One Model of Tax Control. In: Petrosyan L., Mazalov V., Zenkevich N. (eds) Frontiers of Dynamic Games. Static \& Dynamic Game Theory: Foundations \& Applications. Birkhauser, Cham, pp. 121-138. 
Kumacheva, S., Gubar, E., Zhitkova, E., Tomilina, G. (2019). Modeling the behaviour of Economic Agents as a Response to Information on Tax Audits. In: Agarwal N., Sakalauskas L., Weber G.-W. (Eds.) Modeling and Simulation of Social-Behavioral Phenomena in Creative Societies. First International EURO Mini Conference (MSBC 2019) Proceedings, pp. 96-111. Springer International Publishing.

Lambsdorff, J. (2006). The validity and Precision of subjective indicators (CPI). In C. Sampford, A. Shocklock, C. Connors, and F. Galtung, eds., Measuring Corruption, Ashgate, Adelshot, pp. 81-99.

Leite, C., Weideman, J. (1999). Does Mother Nature Corrupt? Natural Resources, Corruption and Economic Growth. IMF Working Paper, 85. Washington: International Monetary Fund.

Levin, A., Lin, C.F., Chu, C.S.J. (2002). Unit root tests in panel data: Asymptotic and finite-sample properties. Journal of Econometrics, 108, 1-24.

Li, H., Squire, L., Zou, H. (1998). Explaining International and Intertemporal Variations in Income Inequality. The Economic Journal, 108, 26-43.

Maddala, G.S., and S. Wu (1999). A comparative study of unit root tests with panel data and a new simple test. Oxford Bulletin of Economics and Statistics, 61, 631-652.

Mauro, P. (1996). The Effects of Corruption on Investment, Growth and Government Expenditure. IMF Working Paper, 98. Washington: International Monetary Fund.

Mauro, P. (1998). Corruption and Composition of Government Expenditure. Journal of Public Economics, 69, 263-79.

Nekovee, A. M., Moreno, Y., Bianconi G. and M. Marsili. (2007). Theory of rumor spreading in complex social networks. Physica A, 374, 457-470.

Olken, Benjamin, 2007. Monitoring corruption: Evidence from a field experiment in Indonesia. Journal of Political Economy, 115(2), 200-249.

Riehl J.R., Cao M. (2015). Control of Stochastic Evolutionary Games on Networks. 5th IFAC Workshop on Distributed Estimation and Control in Networked Systems, Philadelphia, PA, United States, pp. 458-462.

Sandholm, W.H. (2010). Population Games and Evolutionary Dynamics. The M.I.T.Press.

Solt, F. (2011). Standardizing the World Income Inequality Database. Social Science Quarterly, 90(2), 231-242.

Sanchez Carrera, E., Gubar, E. and Oleynik, A. (2018). Network Structures and Poverty Traps. Dynamic Games and Applications, 9(1), 236-253.

Tanzi, V. and H. Davoodi (1998). Corruption, Public Investment, and Growth. In H. Shibata et al. (eds.). The Welfare State, Public Investment, and Growth. Springer-Verlag, Tokyo, pp. 41-60.

Tanzi, V. and H. Davoodi (2000). Corruption, Growth and Public Finances. IMF Working Paper,116, Washington: International Monetary Fund.

Tembine H., Altman E., Azouzi R., Hayel Y. (2010). Evolutionary Games in Wireless Networks. IEEE Transactions on Systems, Man, and Cybernetics. Part B: Cybernetics, 40(3), 634-646.

Vasin, A., Morozov, V. (2005). The Game Theory and Models of Mathematical Economics. Moscow: MAKSpress (in Russian).

Wilhelm, P. G. (2002). International Validation of the Corrupt Perception Index: Implications for Business Ethics and Entrepreneurship Education. Journal of Business Ethics and Entrepreneurship Education, 35(3), 177-189.

Weibull, J. (1995). Evolutionary Game Theory. Cambridge, MA: The M.I.T.Press.

The web-site of the Russian Federation State Statistics Service http://www.gks.ru/ 